\title{
Cancer Research
}

\section{Th-MYCN mice with caspase-8 deficiency develop advanced neuroblastoma with bone marrow metastasis}

Tal Teitz, Madoka Inoue, Marcus B Valentine, et al.

Cancer Res Published OnlineFirst March 27, 2013.

Updated version Access the most recent version of this article at: doi:10.1158/0008-5472.CAN-12-2681

Supplementary Access the most recent supplemental material at:

Material http://cancerres.aacrjournals.org/content/suppl/2013/03/22/0008-5472.CAN-12-2681.DC1.html

Author Author manuscripts have been peer reviewed and accepted for publication but have not yet been Manuscript edited.

E-mail alerts Sign up to receive free email-alerts related to this article or journal.

Reprints and To order reprints of this article or to subscribe to the journal, contact the AACR Publications Subscriptions Department at pubs@aacr.org.

Permissions To request permission to re-use all or part of this article, contact the AACR Publications Department at permissions@aacr.org. 


\section{Th-MYCN Mice with Caspase-8 Deficiency Develop Advanced Neuroblastoma with Bone Marrow Metastasis}

Tal Teitz ${ }^{1}$, Madoka Inoue ${ }^{1}$, Marcus B.Valentine ${ }^{1}$, Kejin Zhu ${ }^{1}$, Jerold E. Rehg ${ }^{2}$, Wei Zhao ${ }^{3}$, David Finkelstein ${ }^{4}$, Yong-Dong Wang ${ }^{5}$, Melissa D. Johnson ${ }^{6}$, Christopher Calabrese ${ }^{6}$, Marcelo Rubinstein ${ }^{7}$, Razqallah Hakem ${ }^{8}$, William A. Weiss ${ }^{9}$ and Jill M. Lahti ${ }^{1 *}$

Authors' Affiliations: ${ }^{1}$ Departments of Tumor Cell Biology, ${ }^{2}$ Pathology, ${ }^{3}$ Biostatistics, ${ }^{4}$ Computational Biology ${ }^{5}$ Hartwell Center for Bioinformatics and Biotechnology and ${ }^{6}$ Animal Imaging Center, St. Jude Children's Research Hospital, Memphis, TN 38105, USA. ${ }^{6}$ Instituto de Investigaciones en Ingeniería Genética y Biología Molecular, Consejo Nacional de Investigaciones Científicas y Tecnológicas and Universidad de Buenos Aires C1428ADN, Argentina. ${ }^{7}$ Department of Medical Biophysics, Ontario Cancer Institute, University of Toronto, Toronto, Ontario M5G 2M9, Canada.

${ }^{8}$ Departments of Neurology, Pediatrics and Neurological Surgery, University of California, San Francisco, CA 94158, USA.

* This article is dedicated to Dr. Jill M. Lahti who passed away on May $30^{\text {th }}$, 2012 after a long and courageous battle with cancer. 
Note: Supplementary data for this article are available at Cancer Research Online (http://cancerres.aacrjournals.org/).

Corresponding Author: Tal Teitz, Department of Tumor Cell Biology, St. Jude Children's Research Hospital, Memphis, TN 38105, USA. Phone: 901595-2156, Fax: 901-595-2381; E-mail: Tal.Teitz@stjude.org

doi:

Running Title- Bone marrow metastasis in a neuroblastoma model

(Key words- caspase-8, metastasis, tumor suppressor, neuroblastoma, mouse model)

The authors disclose no potential conflicts of interest. 


\section{Abstract}

Neuroblastoma, the most common extracranial pediatric solid tumor, is responsible for $15 \%$ of all childhood cancer deaths. Patients frequently present at diagnosis with metastatic disease, particularly to the bone marrow (BM). Advances in therapy and understanding of the metastatic process have been limited due in part, to the lack of animal models harboring BM disease. The widely employed transgenic model, the Th-MYCN mouse, exhibits limited metastasis to this site. Here we establish the first genetic immunocompetent mouse model for metastatic neuroblastoma with enhanced secondary tumors in the BM. This model recapitulates two frequent alterations in metastatic neuroblasoma, over-expression of MYCN and loss of caspase- 8 expression. Mouse caspase- 8 gene was deleted in neural crest lineage cells by crossing a Th-Cre transgenic mouse with a caspase- 8 conditional knockout mouse. This mouse was then crossed with the neuroblastoma prone Th-MYCN mouse. While over-expression of MYCN by itself rarely caused bone marrow metastasis, combining MYCN overexpression and caspase- 8 deletion significantly enhanced BM metastasis (37\% incidence). Microarray expression studies of the primary tumors mRNAs and microRNAs revealed extracellular matrix (ECM) structural changes, increased expression of genes involved in epithelial to mesenchymal transition, inflammation and down-regulation of miR-7a and miR-29b. These molecular changes have been shown to be associated with tumor progression 
and activation of the cytokine transforming growth factor beta (TGF- $\beta$ ) pathway in various tumor models. Cytokine TGF- $\beta$ can preferentially promote single cell motility and blood borne metastasis and therefore activation of this pathway may explain the enhanced BM metastasis observed in this animal model.

\section{Introduction}

Neuroblastoma (NB), a peripheral neural crest-derived childhood solid tumor, is a major medical challenge $(1,2)$. Half of all NB patients have metastatic disease at diagnosis which carries a poor prognosis. Primary human NB tumors arise in the paraspinal ganglia or the adrenal medulla, while disseminated disease appears in the bone marrow (BM, 71\% of patients), bones (56\%), lymph nodes (31\%), lungs (3\%) and other internal organs (15-45\%). The new International Risk Group classification system of the disease divides the patients to 16 risk groups, with the highest risk group being the one that presents with metastasis to the BM and has only $40-50 \%$ survival rate $(2,3)$. The most commonly used preclinical transgenic mouse NB model, the Th-MYCN model (4) exhibits a limited capacity for metastasis to the $\mathrm{BM}(<5 \%$ incidence). In an attempt to establish an immunocompetent genetic metastatic model for NB we crossed two genetically engineered mouse lines, each with a known molecular alteration, common to the 
aggressive disease, amplification of MYCN and loss of expression of caspase8.

MYCN oncogene amplification is frequently seen in aggressive NB and occurs in $25-35 \%$ of human patients (5). Caspase- 8 is a cysteine endoproteinase that cleaves peptide bonds after aspartic acids (6). In addition to its proapoptotic function as an initiator caspase in the extrinsic receptormediated death pathway (6), caspase-8 plays important roles in mediating migration, adhesion, growth, immune response, differentiation, wound healing, fibrosis and necroptosis in certain cell types (7-9). Suppression of caspase- 8 expression by epigenetic silencing occurs in $\sim 70 \%$ of human neuroblastomas (10). Loss of caspase-8 has also been associated with enhancement of the tumorigenic potential of SV40 T-antigen transformed mouse embryonic fibroblasts (11) and with providing an advantage in survival and metastasis of engrafted neuroblastoma cell lines $(12,13)$. Nevertheless, the role of caspase- 8 expression has not been tested thus far in vivo in an immunocompetent mouse model which could have significance given the roles caspase- 8 plays in the immune system.

To circumvent the lethality in CASP8 -/- mice, Salmena and coworkers developed a conditional knockout mouse in which LoxP sites were introduced into the DNA flanking exons 3 and 4 of the mouse caspase- 8 gene (14). We mated these mice with Th-Cre transgenic mice, which express Cre recombinase only in the peripheral neural crest cells and in the brain 
catecholaminergic neurons starting on day E9.5 (15), to selectively delete caspase- 8 in the cells that give rise to neuroblastoma.

Our preliminary results suggested that conditional knockout of caspase- 8 alone was insufficient to induce tumor formation. We studied 30 mice (129X1/SvJ background) harboring two floxed caspase-8 alleles and ThCre for 6-9 months. Tumors did not develop in any of these mice, suggesting that additional genetic alterations are needed. Thus, we tested the hypothesis that the loss of caspase- 8 facilitates $\mathrm{MYCN}-$ induced tumor formation or metastasis by using the Th-MYCN transgenic mouse neuroblastoma model (4). Since mouse genetic background influences tumor penetrance in this model (4), we backcrossed all mouse lines at least 6 generations (6-12) to the $129 \mathrm{X} 1 / \mathrm{SvJ}$ background to ensure that differences in tumor formation were not due to strain variability.

\section{Materials and Methods}

\section{Mouse strains}

Th-MYCN hemizygote mice were purchased from NCI mouse repository (strain \#01XD2) on genetic background 129X1/SvJ and kept on this background. Floxed caspase- 8 mice were received from Razqallah Hakem (14) on 129X1/SvJ, C57BL6 background and backcrossed 6-12 generations to the 129X1/SvJ background. Th-Cre hemizygote mice were received from Dr. Marcello Rubinstein (15) on a B6. $\mathrm{CBF}_{2}$ background and backcrossed 6-12 generations to the $129 \mathrm{X} 1 / \mathrm{SvJ}$ background. This study was carried out in strict 
accordance with the instructions in the Guide to Care and Use of Laboratory Animals of the National Institute of Health. The protocol was approved by the Institutional Animal Care and Use Committee at St. Jude Children's Research Hospital (IACUC protocol 420). All efforts were made to minimize suffering.

\section{Genotyping of mouse tissues and tumors}

Caspase-8 primers:

Sense primer - 5' - CCAGGAAAAGATTTGTGTCTAGC- 3'

Antisense primer - 5'- GGCCTTCCTGAGTACTGTCACCTGT-3'

PCR amplification of the wild-type caspase-8 allele gives a 650-bp band; the caspase- 8 floxed (exons 3 and 4) produces a band of $850 \mathrm{bp}$. Thus, the deleted cre recombinase digested DNA band is $200 \mathrm{bp}$.

Th-Cre primers:

Sense primer - 5'-ATGTCCAATTTACTGACCTACAC- 3'

Antisense primer - 5' - CTAATCGCCATCTTCCAG- 3'

Th-MYCN primers:

Sense primer - 5' - CGACCACAAGGCCCTCAGTA- 3'

Antisense primer - 5' - CAGCCTTGGTGTTGGAGGAG- 3'

\section{Quantative RT-PCR for mouse caspase-8.}

Total RNA was extracted from mouse tumors with Trizol reagent (Life Technologies) and reverse transcribed with Superscript II (Life Technologies). 
Primers for mouse caspase- 8 were employed to PCR amplify a 120-bp fragment from exon 1 to exon 2 of the transcript, thus recognizing wild-type message and floxed caspase- 8 message if stable. Primers used: Sense primer5' - CCCTACAGGGTCATGCTCTT-3' antisense primer- 5' CAGGCTCAAGTCATCTTCCA-3’.

\section{Antibodies and immunohistochemistry.}

For westerns we used antibodies: mouse caspase-8,Cell Signaling cat. 4927, Dil 1:1000, MYCN Cell Signaling cat. 9405, Dil 1:1000, Actin, Santa Cruz cat. 1616, Dil 1:2000. For staining paraffin-embedded formalin fixed tumors and tissues we used antibodies: caspase-8 1H11 Abcam cat. ab119892 dilution 1:200, and anti-Caspase-3, ki67, PGP9.5, synapthophysin, chromogranin A and NFP as described previously (16) .

\section{Ultrasound imaging.}

Ultrasound imaging of the mouse tumors was performed as described recently (16) using the VisualSonics VEVO-770 High frequency Ultrasound system (VisualSonics, Toronto, Canada).

\section{Microarray analysis of neuroblastoma tumor samples}

Total RNA was extracted from primary mouse tumors using Trizol reagent (Life Technologies). Samples were assayed with the Affymetrix Mouse 430v2 GeneChip array and the Agilent mouse microRNA v18 array 
microRNA. Data was summarized by the RMA protocol (17) using Partek Genomics suite 6.6. Outlier samples were detected and removed by PCA and a batch correction corresponding to hybridization date was applied. The data was defined by class and a series of unequal variance $t$ tests were applied to compare classes. Data was visualized and filtered by $p$ value $(0.05)$ and $\log$ ratio and submitted to Gene Set Enrichment Analysis (GSEA, http://www.broadinstitute.org/gsea) to assess Gene Ontology (GO) enrichment. The mRNAs targeted by downregulated microRNAs in the primary tumors samples with BM metastasis were predicted using MirTarget2 (18), and followed by an enrichment analysis using DAVID at NIAID (19). All array data have been deposited in Gene Expression Omnibus at NCBI, and are accessible through GSE42548 (mRNA) and GSE42254 (microRNA). Select array data was validated by qRT-PCR using TaqMan gene expression assays as described in Supplementary Fig. S1.

\section{Results}

\section{Establishing a neuroblastoma mouse model with MYCN amplification and caspase - 8 deficiency}

Neural crest-specific deletion of caspase- 8 in mice was achieved by mating floxed and/or knockout caspase- 8 alleles mice with hemizygous Th-Cre mice and then with hemizygous Th-MYCN mice (Fig. 1A). Four genotypes of 
mice were established: Caspase- ${ }^{\text {fl/fl }}$ (flox/flox), Caspase $8^{\text {fl/ko }}$

(flox/knockout), caspase- ${ }^{\text {wt/ko }}$ (wild type/knockout) and the control caspase- 8 wt/wt (wild type/wild type). Cre-mediated caspase- 8 deletion in the caspase- 8 fl/fl primary tumors was assayed by genomic PCR (Fig. 1B, TU lanes). Caspase- 8 was deleted in the primary tumors at varying efficiencies ranging from a low percentage of cells to complete deletion (Fig. 1B). Caspase-8 expression was also assessed in the primary tumors at the mRNA and protein levels. Most Th-MYCN, Th-Cre, Caspase- $8{ }^{\mathrm{wt} / \mathrm{wt}}($ labeled $+/+$ ) primary abdominal tumors (19 of 20) expressed endogenous caspase-8, as determined by RNA protection (data not shown) and immunoblot assays (Fig. 1C). Caspase- 8 expression in the $\mathrm{wt} / \mathrm{ko}(+/-)$ tumors was reduced to approximately $50 \%$ of wild type, whereas the Th-MYCN, fl/fl and fl/ko caspase- 8 alleles tumors (labeled -/-) had lower caspase-8 expression, around 20\% average, suggesting that the floxed allele is hypomorphic (Fig. 1C and 1D). Levels of caspase- 8 protein in the primary tumors was also determined by immunohistochemistry with anti-caspase- 8 antibody and found to be low or undetectable (Supplementary Fig. S2). The primary deficient caspase-8 tumors stained for neuronal markers typical to neuroblastoma as synapthophysin and PGP9.5 (Supplementary Fig. S3) and were indistinguishable from the wild-type tumors in their incidence, latency, mass (Fig. 1E, 2, 3A and Supplementary Fig. S4). In addition, no statistical significant differences were found in the number of proliferating cells in the primary tumors as determined by Ki-67 staining (both groups had $>95 \%$ 
positive cells, data not shown), or in the number of primary tumor cells undergoing apoptosis as determined by immunostaining with cleaved caspase3 (Supplementary Fig. S5). MYCN expression comparing primary tumors with and without caspase- 8 was also not significantly changed (Supplementary Fig. S6).

\section{Growth characterization of the primary neuroblastoma tumors in the genetically-engineered caspase-8 deficient Th-MYCN mouse model}

Comparison of overall survival and primary tumor onset between the different mouse genetic groups, all on the 129X1/SvJ background, and harboring wild- type or deficient caspase- 8 yielded no significant statistical difference (Fig. 1E and Supplementary Fig. S4) with the limitation that all mice had to be sacrificed after 16-17 weeks due to high primary tumor burden. To determine if there were any changes in the growth or location of the primary tumors prior to this point, we monitored weekly the tumors in both caspase-8-expressing and caspase-8-deleted Th-MYCN mice by ultra-sound imaging (Fig. 2A). No significant differences were found in the frequency or initial location of the tumors. Primary tumors in all mice groups were located in areas surrounding the aorta ( $81 \pm 7 \%$ in both groups) or near the adrenal gland or kidney (19 $\pm 7 \%$ in both groups) (Fig. 2A). In addition, we examined mice at earlier time points (ages 10,21, and 49 days) to determine whether there were variations in the number of initiating preneoplastic hyperplasia cells arising during development in the paraspinal ganglia (Fig. 2B). These 
studies were based on previous work that showed higher frequencies of hyperplastic cells in the paraspinal ganglia of heterozygous Th-MYCN mice compared to $129 \mathrm{X} 1 / \mathrm{SvJ}$ wild-type mice littermates $1-5$ weeks after birth (20, 21). These experiments as well did not reveal any differences in the appearance or incidence of hyperplastic neuroblasts between Th-MYCN mice with and without caspase-8 expression (Fig. 2B), Thus, we conclude that caspase- 8 deficiency does not significantly contribute to initial primary tumor formation.

\section{Caspase-8 deficient Th-MYCN mice have preferentially enhanced neuroblastoma metastasis to the $\mathrm{BM}$}

We then screened Th-MYCN mice harboring advanced-stage primary tumors (ages 9-17 weeks, Fig. 3A) from the wild-type and caspase-8-deficient groups for secondary metastatic tumors to determine whether caspase- 8 plays a role in metastasis in vivo. Detailed necropsy of all major organs was performed (Fig. 3B-3D). In agreement with the data described above, no statistical significant difference was found in the average size of the initial primary tumors (Fig. 3A). We did detect, however, a significant difference in the frequency of secondary tumors in the BM (Fig. 3B and Table 1). Eighty sections were cut from various bones of the mice, including the sternum, the long bones and the vertebra. Tumor cells were identified and the number of BM tumor foci was determined by H\&E staining and immunohistochemistry with the NB markers synapthophysin, tyrosine hydroxylase and/or PGP9.5 
(Table 1). From 27 mice with deficiency in caspase-8 (16 fl/ko and $11 \mathrm{fl} / \mathrm{fl}$, labeled -/-), 10 mice (37\%) had metastatic foci in their BM within 10-17 weeks. The size of the foci ranged from clusters of 5-10 tumor cells to large sheets compromising up to a quarter of the BM cells' population. Twenty one mice with Caspase- $8{ }^{\mathrm{wt} / \mathrm{wt}}$ were screened for BM metastasis and only one mouse ( $4.5 \%$ incidence) had BM metastasis at weeks $10-17$ ( $\mathrm{p}=0.014$, Fig. 3B and $3 \mathrm{D}$ and Table 1). BM tumor cells were negative for caspase- 8 expression as determined by immunostaining (Supplementary Fig. S2) and had very low apoptosis levels (about 1\%) measured by immunostaining for cleaved caspase-3 protein (Supplementary Fig. S5).

The incidence of metastatic dissemination to other organs of the mice, other than the BM (Supplementary Fig. S7) was not significantly enhanced in the caspase-8 deficient group (shown for ovaries, Fig. 3C). The secondary metastatic lesions stained positive for neuronal markers typical for neuroblastoma (Supplementary Fig. S7 shown for PGP9.5). Metastatic ovaries were stained for cleaved caspase- 3 and had 1-2\% percent of cells undergoing apoptosis, equal to the percentage of cells undergoing apoptosis in the matching primary tumors (Supplementary Fig. S5).

\section{Array expression analysis of the caspase-8 deficient primary tumors reveals changes in extracellular matrix $(\mathrm{ECM})$ proteins and tumor cell- ECM interacting proteins}


We compared the mRNA and microRNA expression profiles of a group of 6 primary tumors with wild type caspase- 8 levels in animals with no BM metastasis to a group of 7 primary tumors with deficient caspase- 8 levels in animals that had BM metastasis. Heat map of the top 20 statistically significant genes that differ in expression between the two groups are shown in Figure 4A. The list included genes known to have a role in metastasis, EMT (epithelial to mesenchymal transition), cell detachment from the ECM, fibrosis, wound healing and inflammation as Tfpi2 (Tissue factor pathway inhibitor-2, a serine proteinase inhibitor (22), Snai2 (snail homolog 2 known also as SLUG, a neural crest transcription factor (23), Myct1, myc target 1, a direct c-myc target gene (24), Serpinh1, a serine or cysteine peptidase inhibitor known also as Hsp47, a collagen-specific molecular chaperone (25), Emcn, a mucin-like sialglycoprotein that interferes with the assembly of focal adhesion complexes and inhibits interaction between cells and the $\operatorname{ECM}(26)$ and Fos $(27,28)$. The complete list of genes that are different between the groups and had statistical significance above $\mathrm{p}=0.05$ is in Supplementary Table S1. The list included MMP15, matrix metallopeptidase 15 (29), 1.3 fold increase in the primary tumors with BM metastasis. The complete list of mRNAs was submitted to GSEA and the top enriched gene set was the ECM structural constituents with a nominal p-value of 0.008 (Figure 5). This gene set included upregulation in expression of Tfpi2, LAMA4 (laminin alpha 4 (30, 31)), FBLN2 (fibulin 2), (32), PRELP (ECM protein that functions to 
anchor basement membranes to the underlying connective tissues (33)), COL4A2 (Collagen type 4 alpha 2, $(34,35)$ (Figure 5). mRNA analysis was done also on a group of 10 deficient caspase- 8 mice that did not show metastasis to BM by histology (Figure 4B). The top genes that came up are in Figure 4B and all the gene changes with $\mathrm{p}<0.05$ are included in Supplementary Table S2. This tumor group had 4 genes that overlapped with the metastatic group: Fos (downregulation), Lancll (downregulation), Emcn (upregulation) and Myct1 (upregulation), suggesting these gene expression changes occur before metastasis is observed in the BM.

Analysis of microRNA expression was done on primary tumors with wild type caspase- 8 and no BM metastasis compared to caspase- 8 deficient primary tumors with detected BM metastasis (Table S3). The top microRNAs changes (fold changes $>30 \%$ ) are shown in figure 6 , and included downregulation of miR-29b (1.86 fold) and miR-7a (1.43 fold) expression in the deficient caspase- 8 group. Suppression of miR-29 by TGF$\beta 1 /$ Smad3 signaling has been shown to promote collagen and other ECM components expression and to promote renal fibrosis $(36,37)$. MiR-7 was shown to be suppressed in human neuroblastoma (38), breast cancer and glioblastoma and its downregulation was associated with tumor metastasis $(38,39)$. Its forced expression in tumor cells inhibited EMT transition and metastasis of breast cancer cells via targeting focal adhesion kinase (FAK) expression (39). The mRNAs targeted by the downregulated microRNAs in the primary tumors with BM metastasis in this study were predicted by 
MirTarget 2 and analyzed by gene ontology enrichment. Interestingly, this analysis showed highly enriched expression $\left(p<10^{-6}\right)$ for the identical gene set that came up in the mRNA analysis, the gene set of the ECM structural components as collagens and laminins.

\section{Discussion}

Tumor suppressor genes are defined as genes whose loss of function in tumor cells contribute to the formation and/or maintenance of the tumor phenotype. The findings presented in this report provide proof that caspase- 8 function as a metastatic BM tumor suppressor gene in neuroblastoma. Loss of caspase- 8 expression does not affect primary tumor formation in the ThMYCN mouse but it does promote selective metastasis formation and maintenance in the BM. These results are in accordance with previous studies in mice that showed that a deficiency of TRAIL-R, a protein at the apex of the caspase-8 signaling pathway, enhances metastasis of squamous cell carcinoma to lymph nodes without affecting primary tumor development (40). It also supports the recent clinical findings that a lack of caspase- 8 correlates with relapse in human NB patients evident by BM metastatic disease (10).

Caspase- 8 suppression by epigenetic silencing has also been reported in other human tumors including small cell lung carcinoma, primitive neuroectodermal tumors, alveolar rhabdomyosarcoma, medulloblastoma, and 
retinoblastoma (41). It will be of great interest to investigate whether caspase8 loss can also enhance BM metastasis in these tumors.

Deletion of caspase- 8 in the mouse primary tumor in this animal model was a driver genetic event that led to $\sim 7$ fold increase in Th-MYCN-induced preferential metastasis incidence to the BM (from 5\% average incidence to $37 \%$ ). Interestingly, metastasis to other organs including the abdominal and pulmonary lymph nodes or lungs was not significantly different. This is in contrast to what we previously found by engrafting human cells in the chick embryo or injecting human NB tumor cells deficient in caspase-8 expression directly to the blood stream of immunodeficient mice (12). In these experiments, metastasis incidence of cells with decreased caspase- 8 expression was increased to both the BM and to the lungs at the same frequency. In the animal model studied in this work, we concentrated on the effect of the developing primary tumors on metastasis and determined the transcriptional changes occurring at the primary tumor before and after metastasis are detected in the BM. While we did not find statistical significance changes in the percentage of cells undergoing apoptosis in the primary tumors, we found changes in the ECM structure of the caspase- 8 deficient primary tumors as up regulated expression of collagen 4A2 and laminin $\alpha 4$ once metastasis is detected in the BM. These ECM changes are likely to cause increased stiffness of the primary tumor and changes in mechanotransduction properties which have been shown in different tumor types to correlate with advanced stage of disease (42-44). In addition, we see 
transcriptional changes that would suggest increased motility and migration of the caspase- 8 deficient tumor cells by upregulated expression of genes involved in EMT (as Snai2, Twist1 and TfpI2), enhanced detachment of the tumor cells from the ECM (effected by Emcn, PRELP, miR-7), and increased fibrosis (accumulation of ECM proteins and downregulation of miR-29b). Interestingly, EMT changes have been observed recently in vivo in a breast cancer animal model specifically when the oncogene myc was amplified (45). ECM constituents changes as accumulation of collagens and laminins has been described in fibrosis of tissues and tumors $(9,34,35,37)$ and in wound response processes (8). Caspase-8 down regulation has been linked to wound processes in vivo in which accumulation of collagen and other ECM structural proteins occur (8) and fibrosis is seen in mice that have deficient caspase- 8 in their epidermal tissues (9). In addition, caspase-8 has direct interaction with the ECM proteins by being in complexes with integrins $(12,46)$ and as a part of the focal adhesion complex (7). Deficiency of caspase- 8 in the primary tumors thus could cause changes in the ECM structure and/or possible activation of a wound-like process that triggers deposition of ECM proteins by fibroblasts in the stroma and can activate production of various cytokines. The cytokine transforming growth factor $\beta$ (TGF- $\beta$ ) is one of the major cytokines to be activated in response to wound/injury processes $(47)$, fibrosis $(36,37)$ or as direct changes in the stiffness and mechnotransduction properties of the ECM (48). Importantly for the BM preferential metastasis, TGF- $\beta$ has been shown by intravital imaging experiments to be transiently and locally 
activated in breast cancer motile cells and switch the cells from cohesive to single cell motility (49). Cells restricted to collective invasion were capable of lymphatic invasion but not blood borne metastasis (49). Thus transient activation of TGF- $\beta$ preferentially in the caspase- 8 primary tumors as result of ECM remodeling and/or fibrosis can potentially promote single cell motility, increase invasion to the blood vessels and enhance BM metastasis. Interestingly, we see upregulated expression in the caspase- 8 deficient primary tumors of genes known to be induced by TGF- $\beta$ as Tgif 2 and Tgf $\beta 1$ i1 (Table S1) and downregulation of miR-29b associated with TGF- $\beta$ activation $(36,37)$. Intravital imaging experiments in our caspase- 8 deficient mouse model could shed light if indeed increased blood borne metastasis of single cells contributes to the preferred metastasis to the BM.

In this work we observed downregulation of microRNA-7 expression in the caspase- 8 deficient mouse primary tumors which has been described recently in human neuroblastoma and was associated with metastatic advanced stage (38).

Finally, our finding that the loss of caspase- 8 in the mouse primary tumor cells significantly promotes metastasis to the BM, the most common site for metastasis in human neuroblastoma ( $71 \%$ of patients at diagnosis) (1-3), indicates that this Th-MYCN/caspase-8-deleted animal model should be useful for testing therapies for metastatic neuroblastoma. Ongoing experiments in our laboratory are aimed at purifying the metastatic BM cells for gene expression analysis and surgically resecting or debulking the primary 
tumors to allow even further progression of the metastatic process in the BM.

Our preliminary experiments also indicate the feasibility of establishing orthotopic allograft models using this genetically-engineered model by passaging the primary tumor cells from mice to mice and thus establishing uniform animal cohorts suitable for drug screenings (16). Labeling the primary and secondary metastatic tumor cells in vivo in this animal system by breeding to a fluorescence and/or a luciferase mouse reporter line in which expression of the reporter gene is cre-recombinase mediated (50) is currently in progress and should facilitate the monitoring of tumor cell growth and responses to therapeutic modalities.

\section{Disclosure of Potential Conflicts of Interest}

No potential conflicts of interest were disclosed.

\section{Acknowledgments}

We thank all members of Dr. Jill Lahti's laboratory for discussion, Joshua

Stokes from St. Jude BMC and Judith Hyle for help with preparing the figures, the staff at the St. Jude Veterinary Pathology Core including Sean

Savage, Patricia J. Varner, Dorothy Bush and Pamela Johnson, the staff at the St. Jude Hartwell Center for Bioinformatics and Biotechnology including Dr. Geoffrey Neale, Ridout Granger, Deanna Naeve, Melanie Loyd and John 
Morris and the staff at St. Jude Animal Imaging Shared Resource for assistance.

\section{Grant Support}

The work was funded by NIH grant RO1 CA067938 to J.M.L., Comprehensive Cancer Center Support Grant P30 CA021765, the American Lebanese Associate Charities (ALSAC), NCI grants PO1 CA81403 and RO1 CA102321 to W.A.W.

\section{References}

1. Maris JM. Recent advances in neuroblastoma. N. Engl. J. Med. 2010;362:2202-2211.

2. Owens $\mathrm{C}$ and Irwin $\mathrm{M}$. Neuroblastoma: The impact of biology and cooperation leading to personalized treatments. Critical Reviews in Clinical Laboratory Sciences 2012;49:85-115.

3. Cohn SL, Pearson AD, London WB, Monclair T, Ambros PF, Brodeur

GM, et al. The International Risk Group (INRG) classification system: an INRG Task Force report. J Clin Oncol 2009;27:289-297.

4. Weiss, WA, Aldape K, Mohapatra G, Feuerstein, BG, Bishop, JM.

Targeted expression of MYCN causes neuroblastoma in transgenic mice. EMBO J 1997; 16:2985-2995. 
5. Brodeur GM. Neuroblastoma: Biological insights into a clinical enigma. Nat. Rev. Cancer 2003;3:203-216.

6. Muzio M, Chinnaiyan AM, Kischkel FC, O'Rourke K, Shevchenko A, Ni $\mathrm{J}$ et al. FLICE, a novel FADD-homologous ICE/CED-3-like protease, is recruited to the CD95 (Fas/Apo-1) death-inducing signaling complex. Cell 1996;85:817-827.

7. Teitz T, Jiang M, Twitchell D, Lahti JM. Caspase-8 roles in cancer and development- Lessons in multitasking. Review chapter in: Advances in Genetic Research, 2012;9: Nova Publishers ISBN, 978-1-62081-466-6.

8. Lee P, Lee D, Chan C, Chen S, Ch'en I, Jamora C. Dynamic expression of epidermal caspase 8 simulates a wound healing response. Nature 2009;458:519-524.

9. Li C, Lasse S, Lee P, Nakasaki M, Chen S, Yamasaki K et al. Development of atopic dermatitis-like skin disease from the chronic loss of epidermal caspase-8. PNAS 2010;107:22249-22254.

10. Grau E, Martinez F, Orellana C, Canete A, Yañez Y, Oltra S.et al. Hypermethylation of apoptotic genes as independent prognostic factor in neuroblastoma disease. Molecular Carcinogenesis 2011;50:153-162.

11. Krelin Y, Zhang, L, Kang, TB, Appel E, Kovalenko A, Wallach D. Caspase-8 deficiency facilitates cellular transformation in vitro. Cell Death Differ. 2008;15:1350-1355. 
12. Stupack DG, Teitz T, Potter MD, Mikolon D, Houghton PJ, Kidd VJ et al. Potentiation of neuroblastoma metastasis by loss of caspase- 8 . Nature 2006;439:95-99.

13. Raguėnez G, Mühlerthaler-Mottet A, Meier R, Duros C, Bénard J,Gross N. Fenretinide-induced caspase-8 activation and apoptosis in an established model of metastatic neuroblastoma. BMC Cancer 2009;9:97.

14. Salmena L, Lemmers B, Hakem A, Matysiak-Zablocki E, Murakami K, Au PY et al. Essential role for caspase 8 in T-cell homeostasis and T-cell mediated immunity. Genes \& Dev. 2003;17:883-895.

15. Gelman DM, Noain D, Avale ME, Otero V, Low MJ, Rubinstein M. Transgenic mice engineered to target Cre/LoxP-mediated DNA recombination into catecholaminergic neurons. Genesis 2003;36:196-202.

16. Teitz T, Stanke JJ, Federico S, Bradley CL, Brennan R, Zhang J et al. Preclinical models for neuroblastoma: establishing a baseline for treatment. PLoS One 2011;6:e19133.

17. Irizarry RA, Hobbs B, Collin F, Beazer-Barclay YD, Antonellis KJ, Scherf U et al. Exploration, normalization, and summaries of high density oligonucleotide array probe level data. Biostatistics 2003;4:249-264.

18. Wang $X$. miRDB: a microRNA target prediction and functional annotation database with a wiki interface. RNA 2008;14:1012-1017. 
19. Dennis G, Sherman BT, Hosack DA, Yang J, Gao W, Lane HC et al. DAVID: Database for annotation, visualization, and integrated discovery. Genome Biol. 2003;4:3.

20. Hansford LM, Thomas WD, Keating JM, Burkhart CA, Peaston AE, Norris MD et al. Mechanisms of embryonal tumor initiation: Distinct roles for MycN expression and MYCN amplification. PNAS 2004;101:12664-12669.

21. Alam G, Cui H., Shi H., Yang L, Ding J, Mao L et al. MYCN promotes the expansion of Phox2B-positive neuronal progenitors to drive neuroblastoma development. American J. Pathol. 2009;175:856-866.

22. Neaud V, Hisaka T, Monvoisin A, Bedin C, Balabaud C, Foster DC et al. Paradoxical pro-invasive effect of the serine proteinase inhibitor tissue factor pathway inhibitor-2 on human hepatocellular carcinoma cells. J Biol. Chem. 2000;275:35565-35569.

23. Vitali R, Mancini C, Cesi V, Tanno B, Mancuso M, Bossi G et al. Slug (SNAI2) down-regulation by RNA interference facilitates apoptosis and inhibits invasive growth in neuroblastoma preclinical models. Clin Cancer Res 2008;14:4622-4630.

24. Rogulski KR, Cohen DE, Corcoran DL, Benos PV, Prochownik EV. Deregulation of common genes by c-Myc and its direct target, MT-MC1. PNAS 2005;102:18968-18973. 
25. Yang Q, Liu S, Tian Y, Hasan C, Kersey D, Salwen, HR. Methylationassociated silencing of the heat shock Protein 47 gene in human neuroblastoma. Cancer Res 2004;64:4531-4538.

26. Kinoshita M, Nakamura T, Ihara M, Haraguchi T, Hiraoka Y, Tashiro K. Identification of human endomucin-1 and -2 as membrane-bound Osialoglycoproteins with anti-adhesive activity. FEBS Letters 2001;499:121-126.

27. Ordway JM, Williams K, Curran T. Transcription repression in oncogenic transformation: common targets of epigenetic repression in cells transformed by Fos, Ras or Dnmt1. Oncogene 2004;23:3737-3748.

28. Ostler KR, Yang Q, Looney TJ, Zhang L, Vasanthakumar A, Tian Y et al. Truncated DNMT3B isoform DNMT3B7 supresses growth, induces differentiation, and alters DNA methylation in human neuroblastoma. Cancer Res 2012;72:4714-4723.

29. Tao G., Levay AK, Gridley T, Lincoln J. Mmp15 is a direct target of Snail during endothelial to mesenchymal transformation and endocardial cushion development. Dev Biol 2011;359:209-221.

30. Sprenger CCT, Drivdahl RH, Woodke LB, Eyman D, Reed MJ, Carter WG et al. Senescence-induced alterations of laminin chain expression modulate tumorigenicity of prostate cancer cells. Neoplasia 2008;10:1350-1361.

31. Huang X, Ji G, Wu Y, Wan B, Yu L. LAMA4, highly expressed in human hepatocellular carcinoma from Chinese patients, is a novel marker 
of tumor invasion and metastasis. J Cancer Res Clin Oncol $2008 ; 134: 705-714$.

32. Law EWL, Cheung AKL, Kashuba VI, Pavlova TV, Zabarovsky ER, Lung HL et al. Anti-angiogenic and tumor-suppressive roles of candidate tumor-suppressor gene, Fibulin-2 in nasopharyngeal carcinoma. Oncogene 2012;31:728-738.

33. Happonen KE., Furst CM, Saxne T, Heinegard D, Blom AM. PRELP protein inhibits the formation of the complement membrane attack complex. J Biol Chem. 2012;287:8092-8100.

34. Bianchini G, Qi Y, Alvarez RH, Iwamoto T, Coutant C, Ibrahim NK et al. Molecular anatomy of breast cancer stroma and its prognostic value in estrogen-receptor positive and-negative cancers. J Clin Oncol 2010;28:4316-4323.

35. Stewart DA, Cooper CR, Sikes RA. Changes in extracellular matrix (ECM) and ECM-associated proteins in the metastatic progression of prostate cancer. Reprod Biol Endocrinol 2004;7:2-15.

36. Qin W, Chung ACK, Huang XR, Meng X, Hui DSC, Yu C et al. TGF$\beta /$ Smad3 signaling promotes renal fibrosis by inhibiting miR-29. J Am Soc Nephrol 2011;22:1462-1474.

37. Wang B, Komers R, Carew R, Winbanks CE, Xu B, Herman-Edelstein M et al. Suppression of microRNA-29 expression by TGF $\beta$-1 promotes collagen expression and renal fibrosis. J Am Soc Nephrol 2012;23:252265. 
38. Guo J, Dong Q, Fang Z, Chen X, Lu H, Wang K et al. Identification of microRNAs that are associated with tumor metastasis in neuroblastoma. Cancer Biol Ther 2010;9:446-452.

39. Kong X, Li G, Yuan Y, He Y, Wu X, Zhang W et al. MicroRNA-7 inhibits epithelial-to-mesenchymal transition and metastasis of breast cancer cells via targeting FAK expression. PLoS ONE;2012:7:e41523.

40. Grosse-Wilde A, Voloshanenko O, Bailey SL, Longton GM, Schaefer U, Csernok AI et al. TRAIL-R deficiency in mice enhances lymph node metastasis without affecting primary tumor development. J. Clin. Invest. 2008;118:100-110.

41. Fulda S. Caspase-8 in cancer biology and therapy. Cancer Lett. 2009;281:128-133.

42. Lu P, Weaver VM, Werb Z. The extracellular matrix: A dynamic niche in cancer progression. J Cell Biol. 2012;196:395-406.

43. Butcher DT, Alliston T, Weaver VM. A tense situation: Forcing tumour progression. Nat. Rev. Cancer 2009;9:108-122.

44. Jaalouk DE, Lammerding J. Mechanotransduction gone awry. Nature Rev. Mol. Cell Biol. 2009;10:63-73.

45. Trimboli AJ, Fukino K, Bruin A, Wei G, Shen L, Tanner SM et al. Direct evidence for epithelial-mesenchymal transitions in breast cancer. Cancer Res 2008;68:937-945.

46. Lahti JM, Teitz T., Stupack DG. Does integrin-mediated cell death confer tissue tropism in metastasis? Cancer Res 2006;66:5981-5984. 
47. Anscher MS. Targeting the TGF- $\beta 1$ pathway to prevent normal tissue injury after cancer therapy. The Oncologist 2010;15:350-359.

48. Maeda T, Sakabe T, Sunaga A, Sakai K, Rivera AL, Keene DR et al. Conversion of mechanical force into TGF- $\beta$-mediated biochemical signals. Current Biology 2011;21:933-941.

49. Giampieri S, Manning C, Hooper S, Jones L, Hill CS, Sahai E. Localized and reversible TGFbeta signaling switches breast cancer cells from cohesive to single cell motility. Nat Cell Biol 2009;11:1287-1296.

50. Madisen L, Zwingman TA, Sunkin SM, Oh SW, Zariwala HA, Gu H et al. A robust and high-throughout Cre reporting and characterization system for the whole mouse brain. Nat. Neurosci. 2010;13:133-140.

Figure Legends

Figure 1. Characterization of the tumors formed in the Th-MYCN, ThCre,caspase-8 deleted mice (fl/fl, fl/ko or wt/ko caspase-8).

(A) Deficient caspase-8, Th-MYCN mice were obtained by mating floxed or heterozygous caspase- 8 alleles mice with hemizygous Th-Cre mice and then with hemizygous Th-MYCN mice.

(B) Validation of caspase- 8 deletion status in the primary Th-MYCN, Th-Cre, caspase- $8{ }^{\mathrm{fl} / \mathrm{fl}}$ neuroblastoma tumors using genomic PCR. Tail DNA (TA) 
from mice with tumors and primay tumor DNA (TU) was amplified using primers flanking exons 3 and 4 of mouse caspase- 8 gene. Only the Casp ${ }^{\mathrm{fl}}$ band were detected in the tail samples while the Casp8 ${ }^{\mathrm{fl}}$ and the deleted caspase- 8 bands (Casp ${ }^{\text {del }}$ ) were detected in varying levels in the primary tumors. PCR amplification of the casp8fl3-4 allele $\left(\mathrm{Casp} 8{ }^{\mathrm{fl}}\right)$ generates a band of $850 \mathrm{bp}$ and the deleted band $\left(\mathrm{Casp} 8^{\mathrm{del}}\right)$ is $200 \mathrm{bp}$.

(C) Western blots analysis of primary neuroblastoma tumors with an antimouse caspase- 8 antibody. - -/- mice are the Casp $8 \mathrm{fl} / \mathrm{fl}$ and caspase $8 \mathrm{fl} / \mathrm{ko}$ mice.

(D) Quantative RT-PCR analysis for mouse caspase-8 was performed on total RNA extracted from the primary tumors of the following Th-MYCN, Th-Cre mouse genetic groups: wt/wt caspase- $8, n=8$, wt/ko caspase- $8 \mathrm{n}=5, \mathrm{P}=0.007$ compared to $\mathrm{wt} / \mathrm{wt}, \mathrm{fl} / \mathrm{ko}$ caspase- $8, \mathrm{n}=6, \mathrm{P}=0.003$ compared to wt/wt, $\mathrm{P}$ values determined by $t$ test.

(E) Kaplan-Meier survival curves of the Th-MYCN, Th-Cre mice with wt/wt caspase- $8(\mathrm{n}=85)$ or $\mathrm{fl} / \mathrm{fl}$ caspase- $8(\mathrm{n}=90, \mathrm{P}=0.12$ compared to $\mathrm{wt} / \mathrm{wt})$, or $\mathrm{fl} / \mathrm{ko}$ caspase- $8(\mathrm{n}=90, \mathrm{P}=0.30$ compared to $\mathrm{wt} / \mathrm{wt})$, or caspase- 8 heterozygous $w t / k o(n=43, P=0.21$ compared to $w t / w t)$. $P$ values were determined by Gehan-Breslow-Wilcoxon log-rank test.

Figure 2. Caspase-8 deficiency does not change the incidence, latency, location, or growth rate of the mouse primary neuroblastoma tumors. 
(A) Primary tumors could be identified by ultrasound imaging starting at mouse age 6-7 weeks. Tumors (red) arose in Th-MYCN, Th-Cre, wt/wt caspase-8 or Th-MYCN, Th-Cre, caspase-8-deficient mice (fl/ko and fl/fl caspase-8) in the paravertebral ganglia, either surrounding or near the aorta (purple) $(81 \pm 7 \%$ of the cases) or near the kidney (green) and adrenal gland ( $19 \pm 7 \%$ of the cases), $n=28$ for the wt caspase- 8 group and $n=41$ for the caspase-8-deficient group.

(B) Typical examples of preneoplastic islets observed in mice with caspase- 8 wt/wt, Th-MYCN $(n=10)$ or deficient caspase-8, Th-MYCN $(n=9)$ at ages 10, 21, and 49 days are shown (H\&E). No preneoplastic islets were observed in mice without MYCN. Arrows point to- LN- lymph node, PN- preneoplastic lesions, BM- BM, A- aorta, VE- vertebra, GN- ganglia. Scale bar represents $50 \mu \mathrm{m}$.

\section{Figure 3. Deficiency of caspase-8 in the Th-MYCN mouse model enhances metastasis preferentially to the BM.}

(A) No significant difference in the mean mass of the primary neuroblastoma tumors of the Casp $8^{\mathrm{wt} / \mathrm{wt}}$, Th-MYCN, mouse group and the caspase- 8 deficient (Casp8 ${ }^{\mathrm{fl} / \mathrm{ko}}$ and $\mathrm{Casp} 8^{\mathrm{fl} / \mathrm{fl}}$ mice, labeled -/-), Th-MYCN mice at the time interval metastasis was assayed ( $14 \pm 6$ wks old mice). Data are expressed as mean \pm s.e.m ( $\mathrm{n}=12$ for both mouse groups).

(B) A significantly higher incidence of metastatic neuroblastoma was found in the BM of the caspase-8-deficient mouse group compared to the wt caspase- 8 
group ( $\mathrm{n}=21$ wt caspase- 8 mice and $\mathrm{n}=28$ caspase- 8 -deficent, $* \mathrm{P}=0.014, \mathrm{P}$

determined by Fisher's exact test).

(C) Metastatic incidence to the ovaries did not differ statistically between the wt caspase- 8 group and the deficient caspase- 8 group ( $n=7$ wt caspase- $8, n=9$, caspase-8-deleted, $\mathrm{P}=0.10$ by Fisher's exact test).

(D) Typical examples of H\&E staining of the secondary tumors in the BM of caspase-8-deficient mice in long bones such as the femur, tibia, and humerus. The BM metastatic tumor cells stained positive for the neuronal markers synapthophysin and tyrosine hydroxylase. Areas of tumor cells in the BM are marked with arrows and asterisks indicate bones. Th-MYCN mouse BM with no metastasis serves as control. Scale bar is $50 \mu$ m except in images $1,3,4$ and 6 from left top it is $200 \mu \mathrm{m}$.

Figure 4. Heat map of the top 20 genes that are differentially expressed in the primary tumors $(\mathbf{p}<0.05)$.

\section{Figure 5. GSEA enrichment plot of GO term ECM structural}

\section{constituent.}

Genes in the GO term ECM constituent showed significant enrichment in BM metastasis versus no BMM samples. The top portion of the figure plots the enrichment score for each gene, and the bottom portion shows the values of the ranking metric moving down the list of the ranked genes. The table 
Author Manuscript Published OnlineFirst on March 27, 2013; DOI: 10.1158/0008-5472.CAN-12-2681

Author manuscripts have been peer reviewed and accepted for publication but have not yet been edited.

indicates that the majority of the genes in the term were significantly enriched and upregulated in the caspase- 8 deficient BMM samples.

Figure 6. microRNAs that are differentially expressed in the caspase-8 deficient primary tumors. 
Table 1. Metastasis to the bone marrow in the TH-MYCN deleted caspase-8 mice

\begin{tabular}{|l|l|l|l|l|l|}
\hline $\begin{array}{l}\text { Casp8 } \\
\text { genotype }\end{array}$ & $\begin{array}{l}\text { Mouse } \\
\text { Number(s) }\end{array}$ & $\begin{array}{l}\text { Age } \\
(\mathrm{wks})\end{array}$ & Sternum & $\begin{array}{l}\text { Long } \\
\text { bones }\end{array}$ & Vertebra \\
\hline $\mathrm{wt} / \mathrm{wt}$ & $1-20$ & $10-17$ & $\mathrm{~N}$ & $\mathrm{~N}$ & $\mathrm{~N}$ \\
\hline $\mathrm{wt} / \mathrm{wt}$ & 21 & 10 & $\mathrm{~N}$ & $2^{\mathrm{a}}$ & 1 \\
\hline $\mathrm{fl} / \mathrm{ko}$ & $1-10$ & $10-17$ & $\mathrm{~N}$ & $\mathrm{~N}$ & $\mathrm{~N}$ \\
\hline $\mathrm{fl} / \mathrm{ko}$ & 11 & 10 & $\mathrm{~N}$ & $\mathrm{~N}$ & 1 \\
\hline $\mathrm{fl} / \mathrm{ko}$ & 12 & 9 & $\mathrm{~N}$ & $\mathrm{~N}$ & 1 \\
\hline $\mathrm{fl} / \mathrm{ko}$ & 13 & 10 & $\mathrm{~N}$ & $\mathrm{~N}$ & 1 \\
\hline $\mathrm{fl} / \mathrm{ko}$ & 14 & 17 & $\mathrm{~N}$ & $1^{\mathrm{a}}$ & $\mathrm{N}$ \\
\hline $\mathrm{fl} / \mathrm{ko}$ & 15 & 16 & $\mathrm{~N}$ & 1 & 1 \\
\hline $\mathrm{fl} / \mathrm{ko}$ & 16 & 10 & $\mathrm{~N}$ & 1 & $\mathrm{~N}$ \\
\hline $\mathrm{fl} / \mathrm{fl}$ & $1-7$ & $10-17$ & $\mathrm{~N}$ & $\mathrm{~N}$ & $\mathrm{~N}$ \\
\hline $\mathrm{fl} / \mathrm{fl}$ & 8 & 10 & $\mathrm{~N}$ & $1^{\mathrm{a}}$ & $\mathrm{N}$ \\
\hline $\mathrm{fl} / \mathrm{fl}$ & 9 & 11 & $\mathrm{~N}$ & $\mathrm{~N}$ & 1 \\
\hline $\mathrm{fl} / \mathrm{fl}$ & 10 & 10 & 1 & $6^{\mathrm{a}}$ & $1^{\mathrm{a}}$ \\
\hline $\mathrm{fl} / \mathrm{fl}$ & 11 & 11 & $\mathrm{~N}$ & 1 & $\mathrm{~N}$ \\
\hline & & & & & \\
\hline & & & & & \\
\hline
\end{tabular}

$\mathrm{n}=21$ for $\mathrm{wt} / \mathrm{wt}$ casp- 8 mice, $\mathrm{n}=16$ for $\mathrm{fl} /$ ko casp- 8 mice and $\mathrm{n}=11$ for $\mathrm{fl} / \mathrm{fl}$ casp- 8 mice Mice with metastasis to BM are labeled in red and were generated from at least 3-4 mating combinations during a 2 year period.

$\mathrm{N}$ - No tumor cells detected.

${ }^{\mathrm{a}}$ Neuroblastoma cells were confirmed by immunohistochemistry with synapthopysin, tyrosine hydroxylase and/or PGP9.5 antibodies and by morphology after H\&E stain. Numbers in table indicate independent foci ranging in size from a cluster of 5-10 tumor cells to large sheets of cells. 

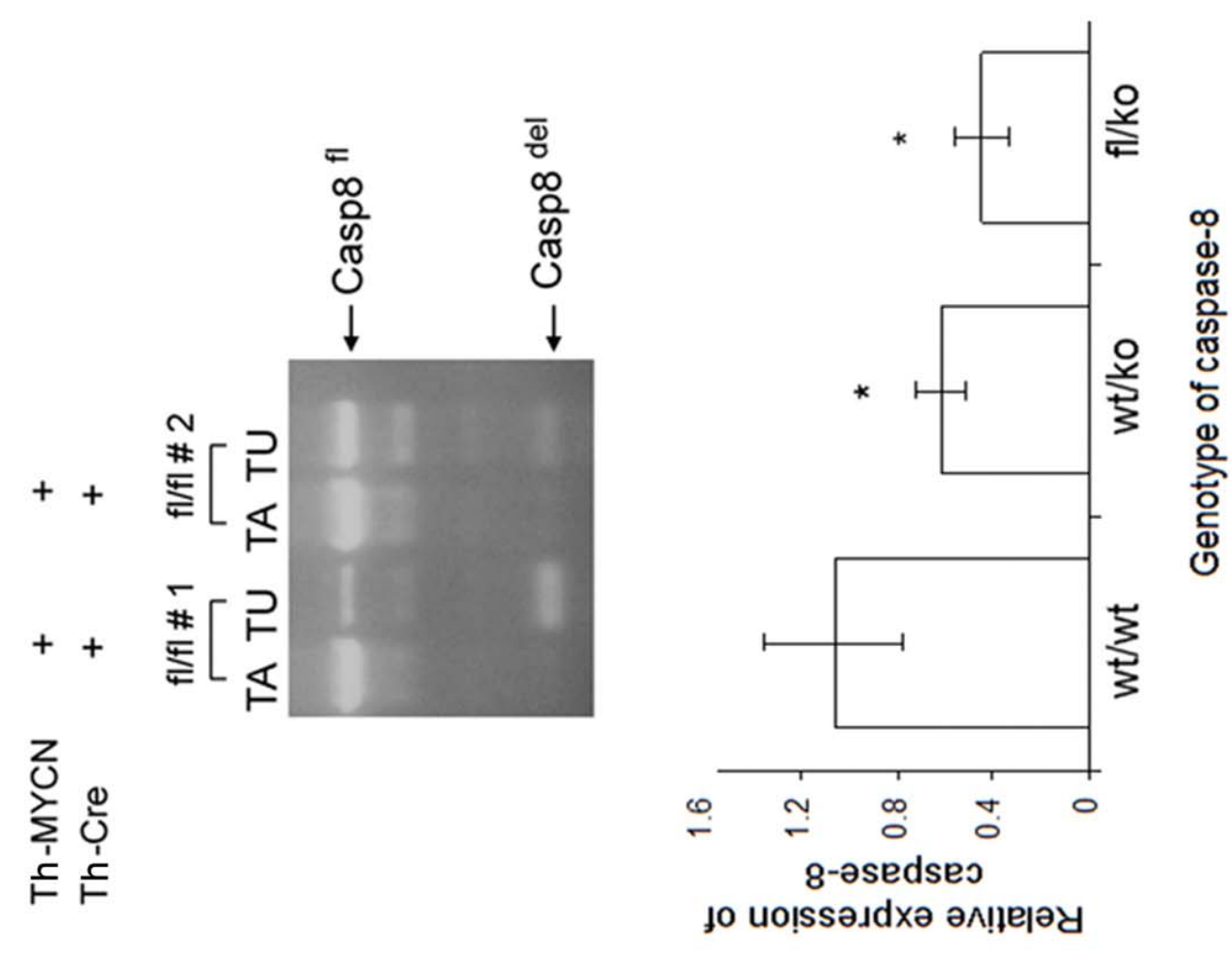

$m$
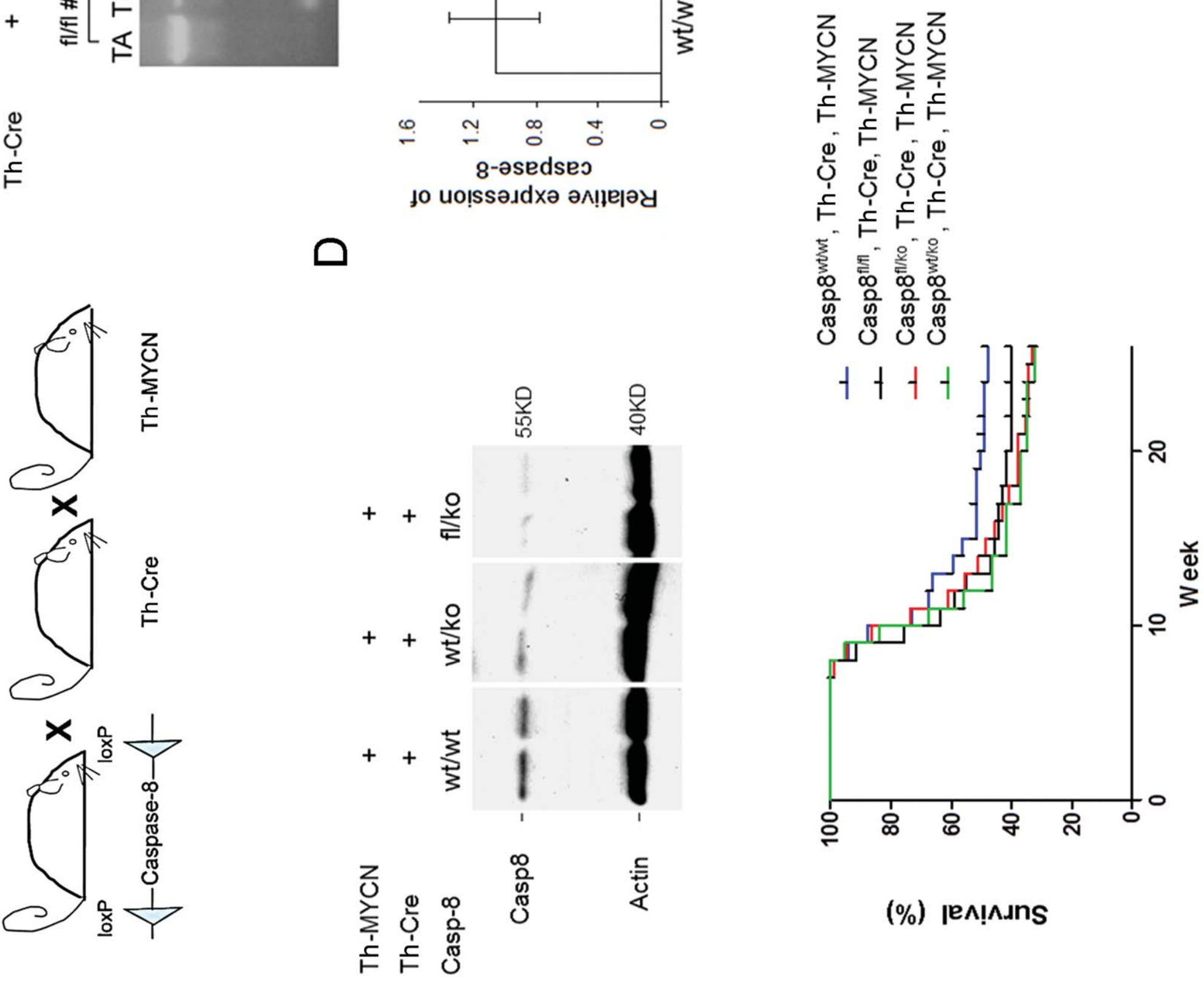

(\%) ןอ^!n..nns 


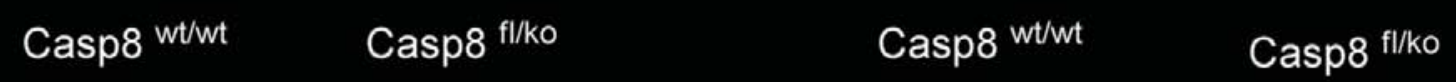

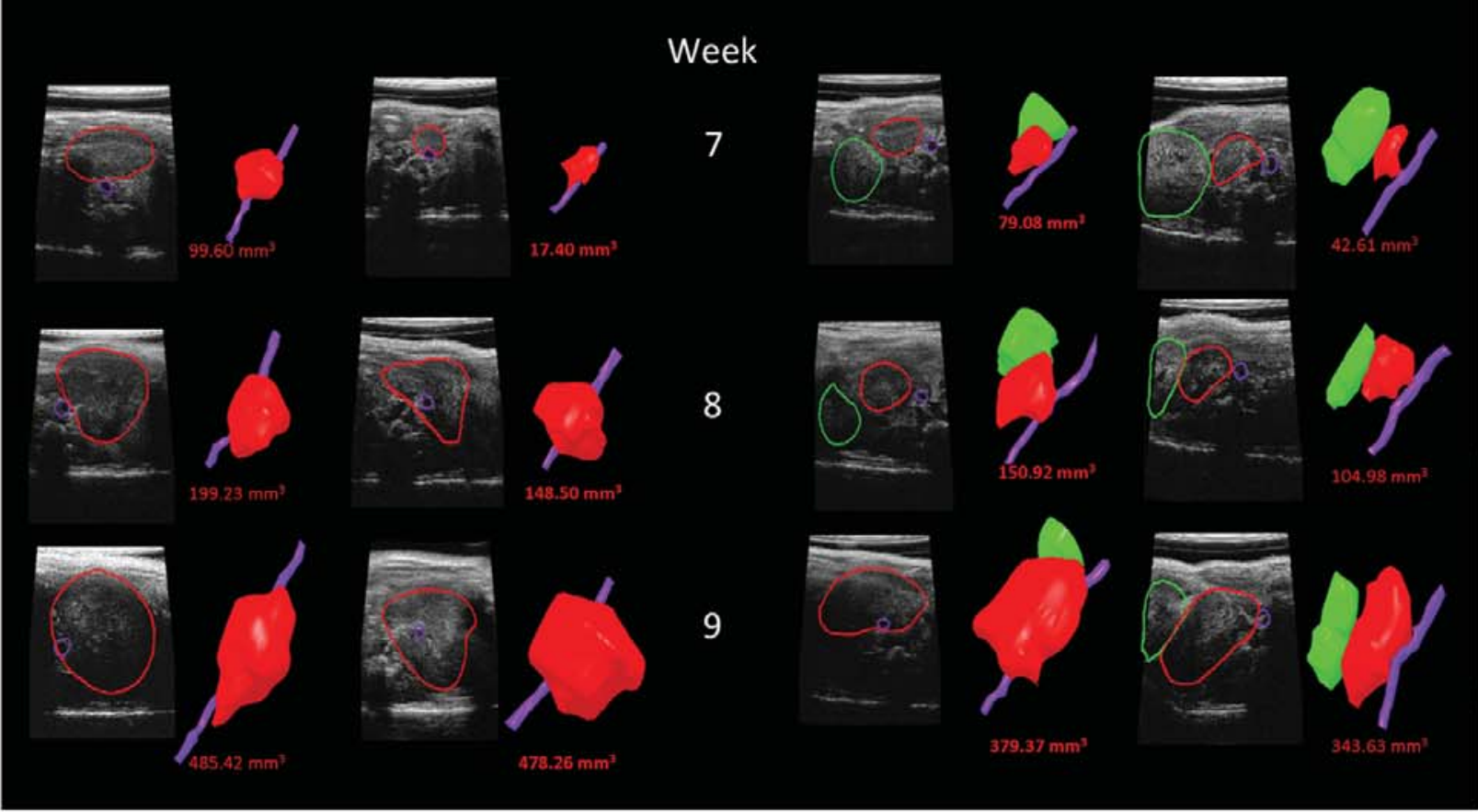

Th-MYCN, casp8 $8^{\text {wt/wt }}$ or casp8 $8^{f / k o}$

B

10 days
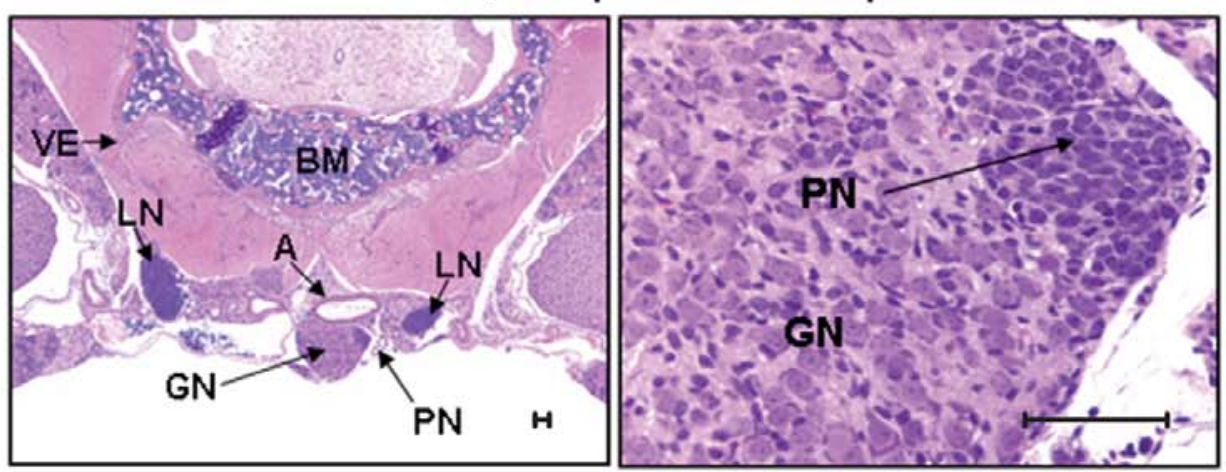

casp8 $8^{\text {wt/wt }}$ or casp8 $8^{\text {fl/ko }}$

21 days
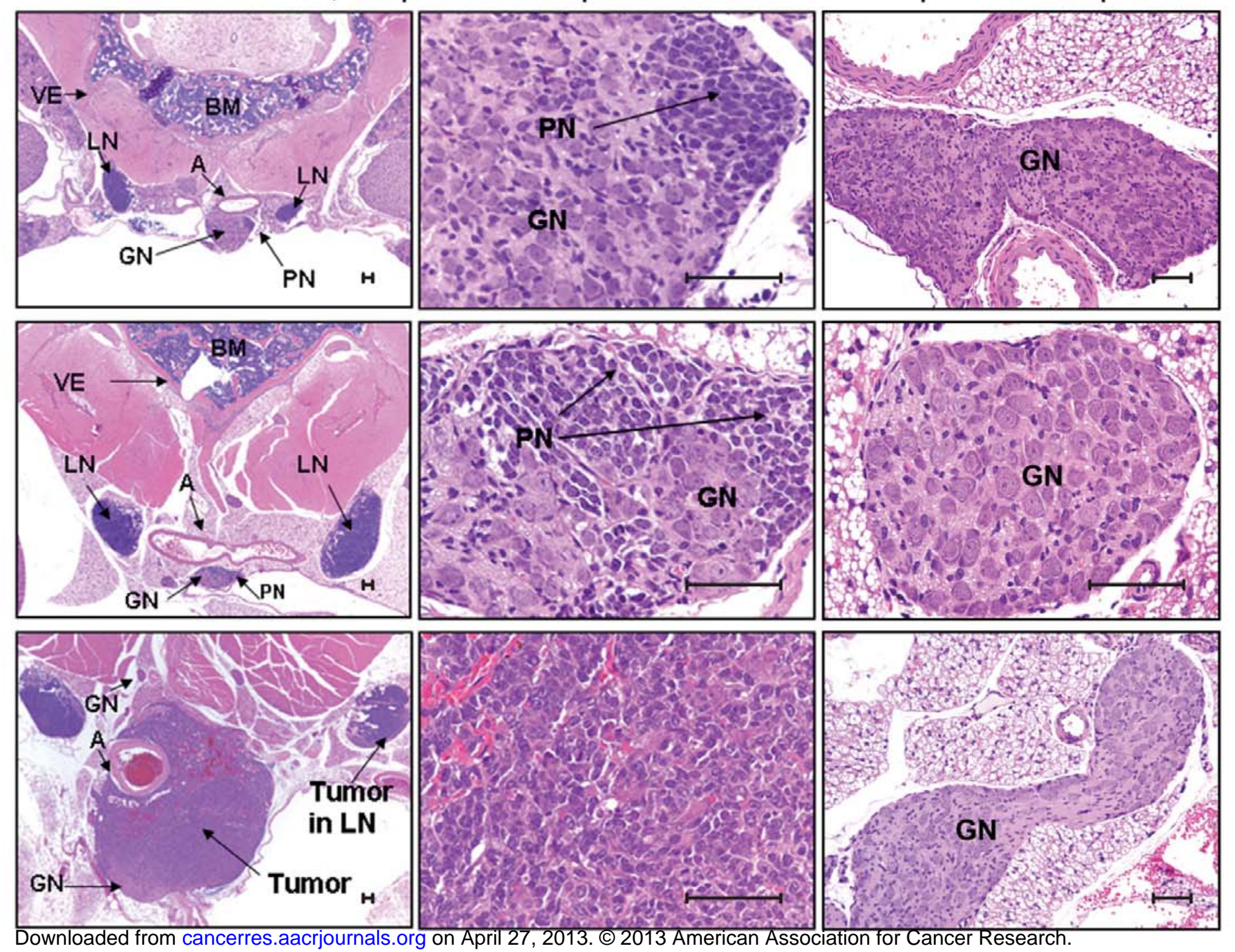


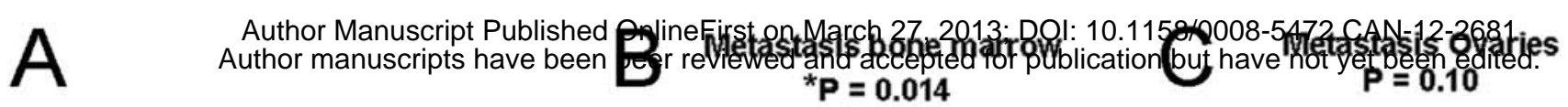

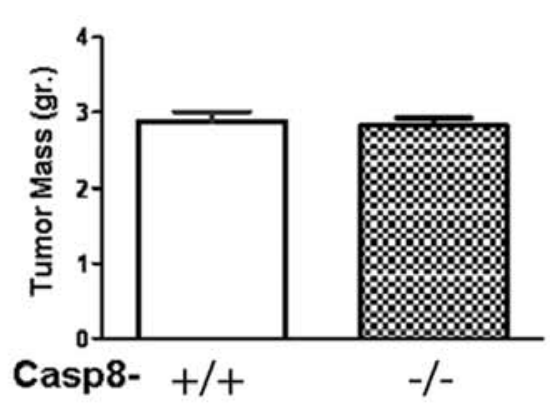

Primary Th $-\mathrm{MYCN}$, Th-Cre
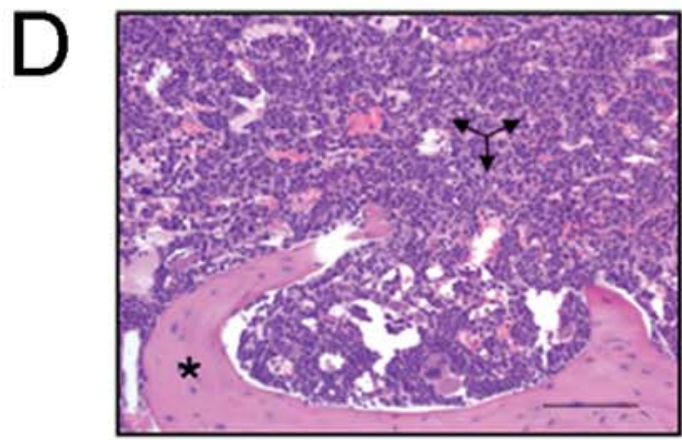

BM mouse A, femur H\&E

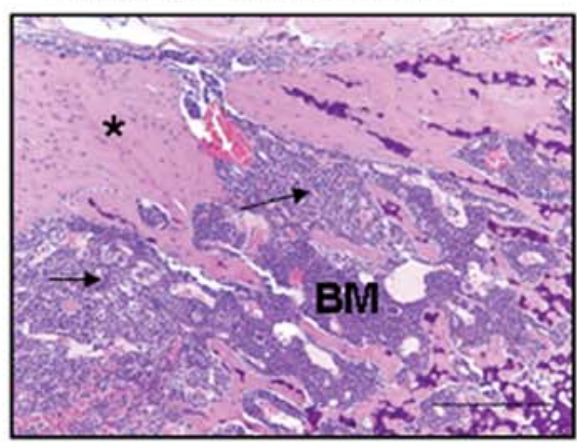

BM mouse $B$, Tibia H\&E

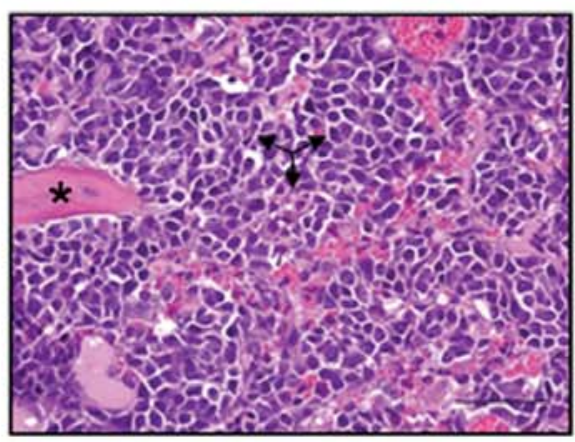

BM mouse $B$, humerus H\&E

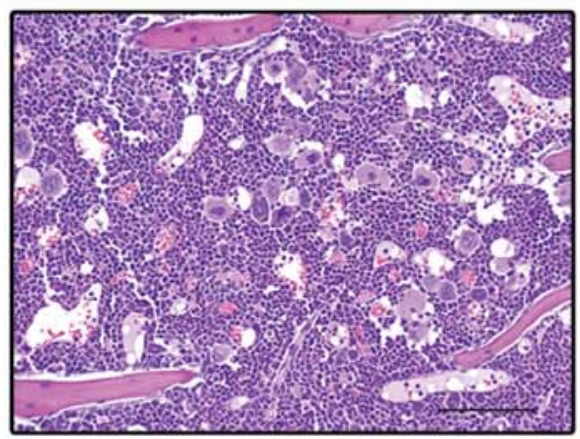

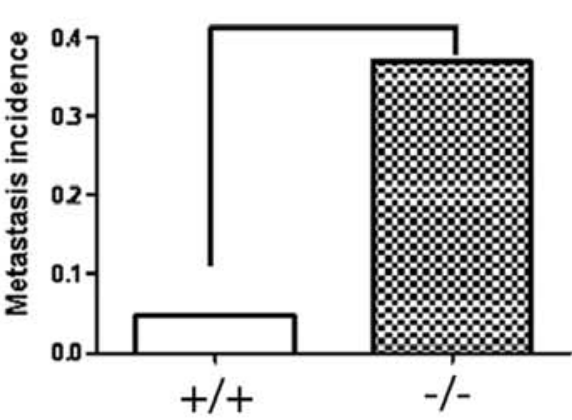

Th-MYCN, Th-Cre mice

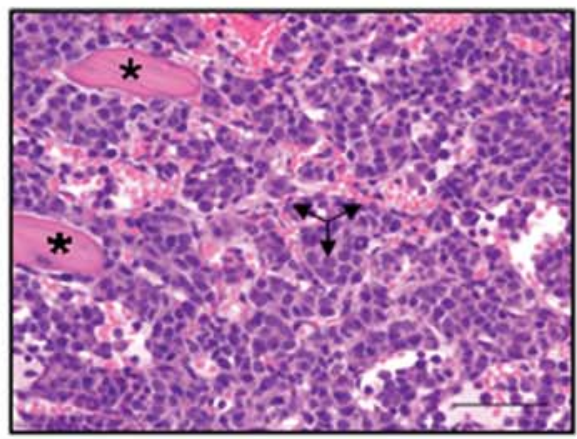

BM mouse A, femur H\&E

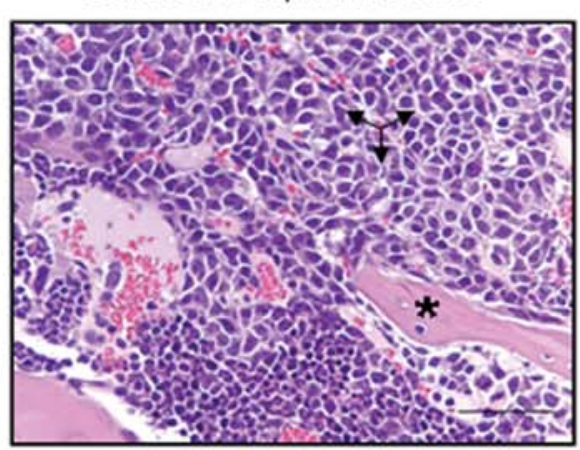

BM mouse B. Tibia H\&E

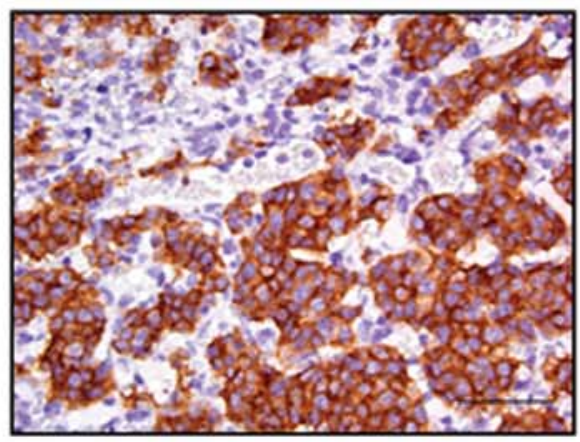

BM mouse $B$, humerus SNP

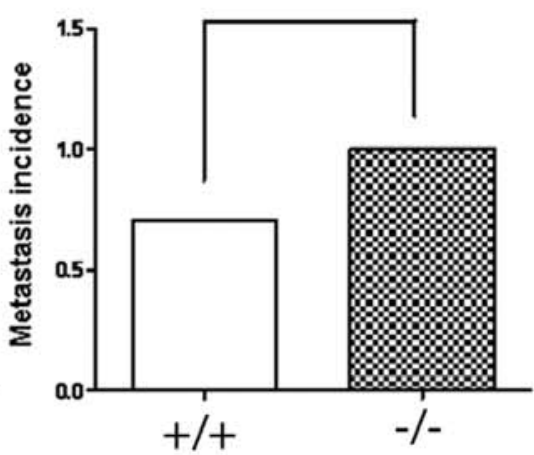

Th-MYCN, Th-Cre mice

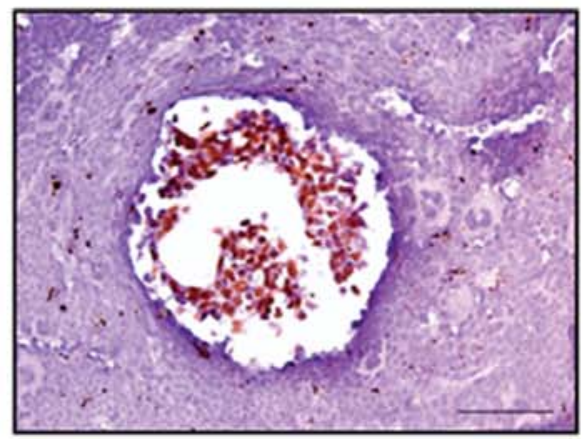

BM mouse A, R. leg SNP

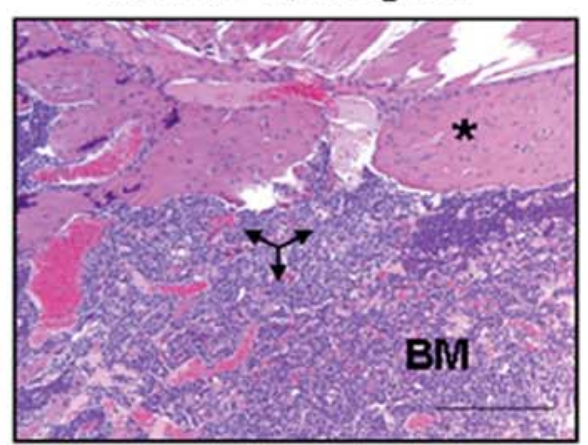

BM mouse B. Humerus H\&E

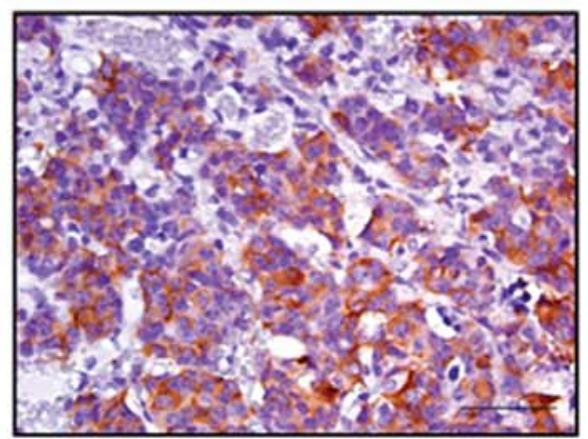

BM mouse $B$, humerus TH

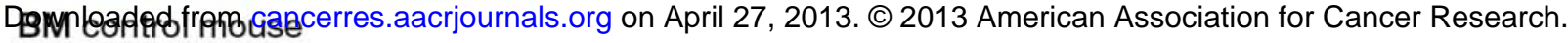




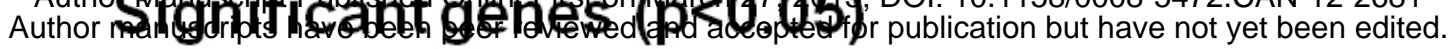

A.

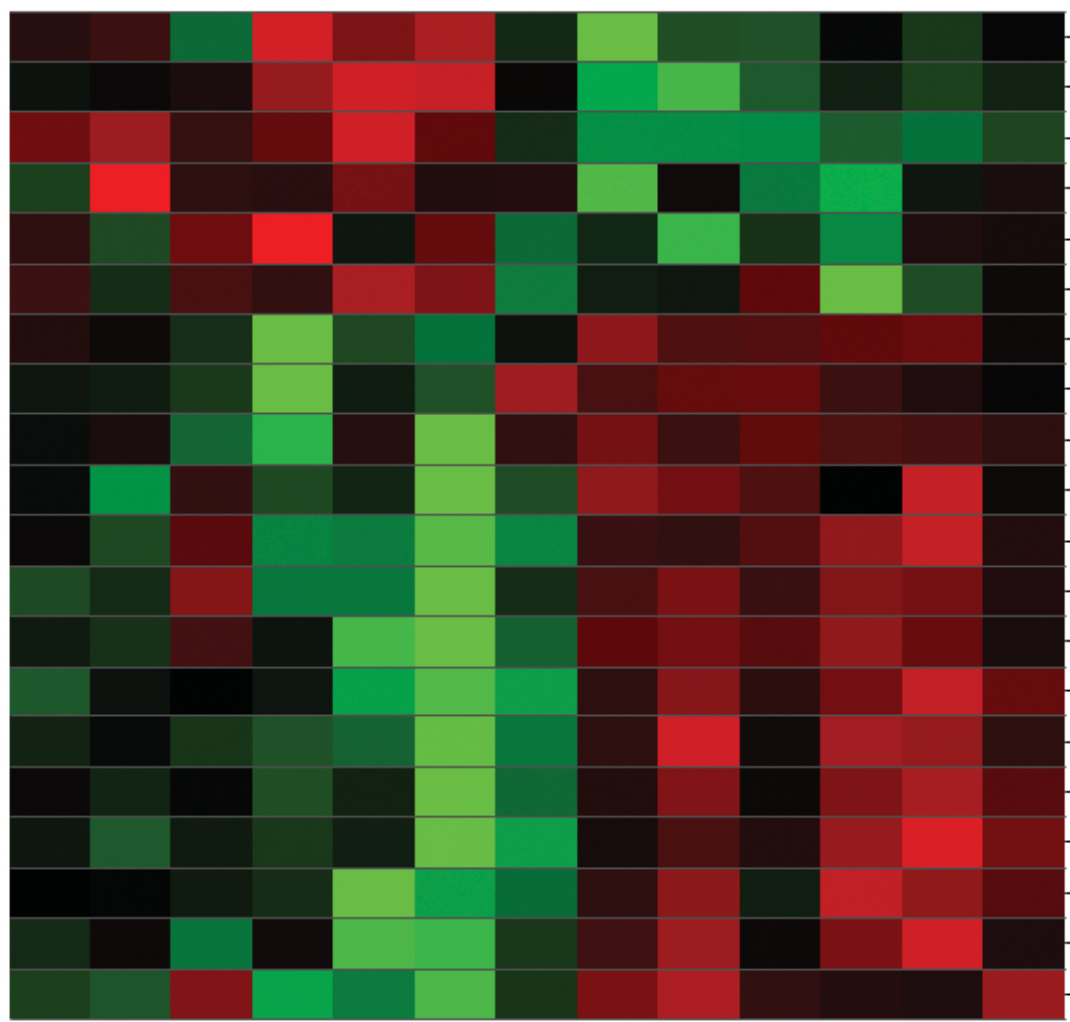

Plcb4

-Rraga

Lancl1

Fos

-Ap1s3

-Calb1

$-\mathrm{Mbn} / 3$

$-\mathrm{Ak} 5$

Gm5868/// Slc10a4

-Tfpi2

-Snai2

-Tagln

-Serpinh 1

-1810011010Rik

-Mmrn2

-Ptprb

Emcn

-Btn19

-Myct1

-Chrdl1

Wild type caspase- 8

no BM metastasis
Deficient caspase-8

with BM metastasis $\begin{array}{lll}-2 & 0 & 2\end{array}$

heat map color

scale

std dev units

B.

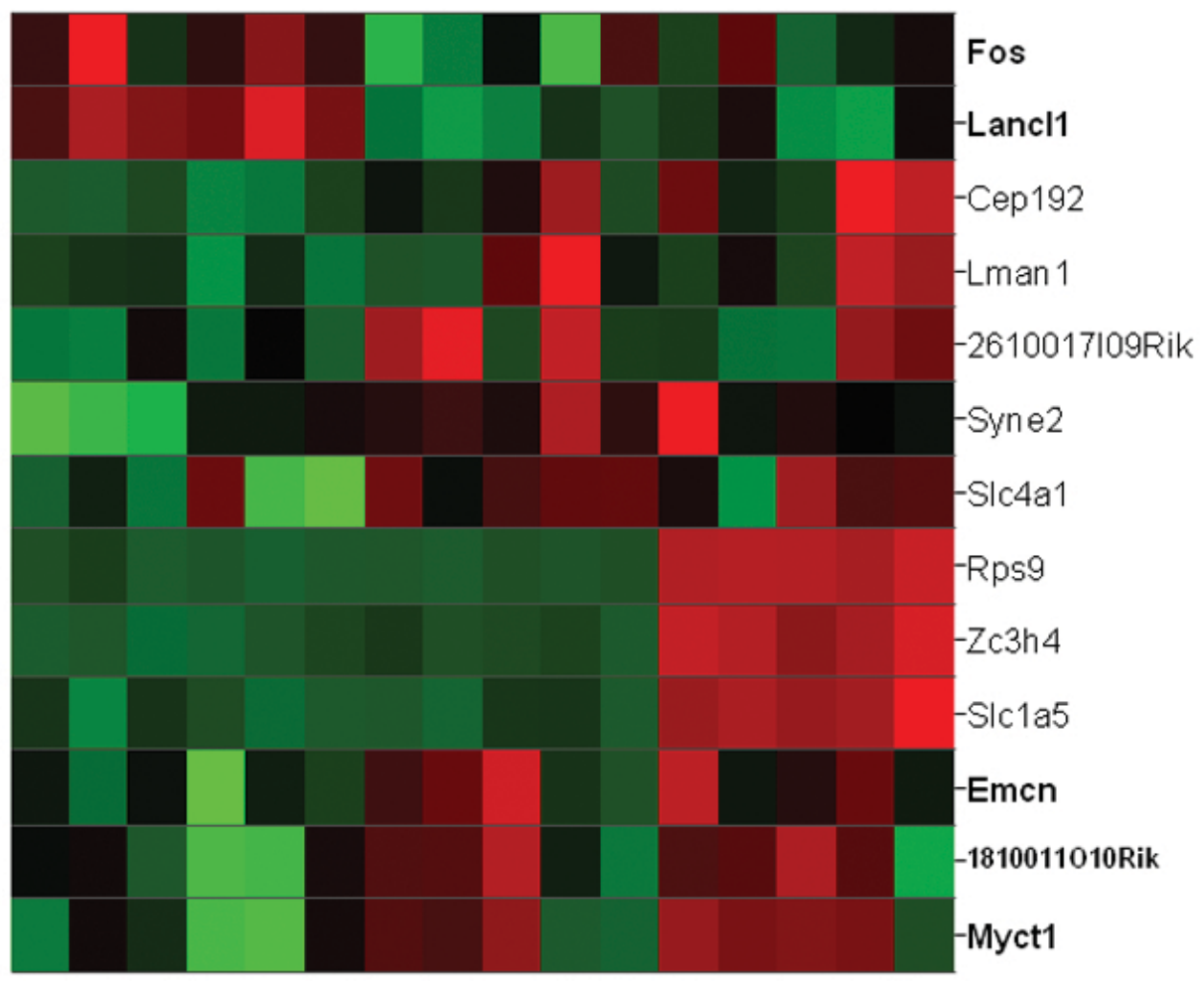

\section{Wild type caspase- 8 no BM metastasis}
Deficient caspase- 8 No BM metastasis


Author Manuscript Published OnlineFirst on March 27, 2013; DOI: 10.1158/0008-5472.CAN-12-2681

Author manuscripts have been peer reviewed and accepted for publication but have not yet been edited.

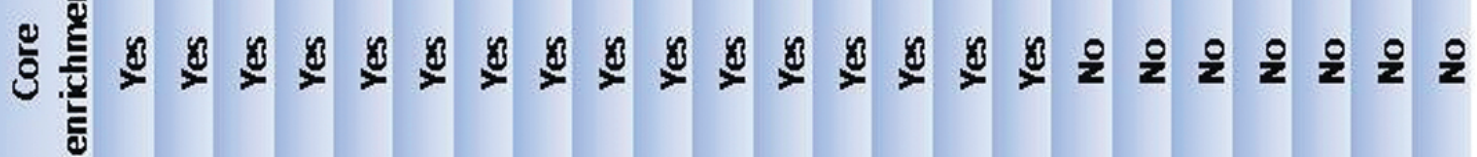

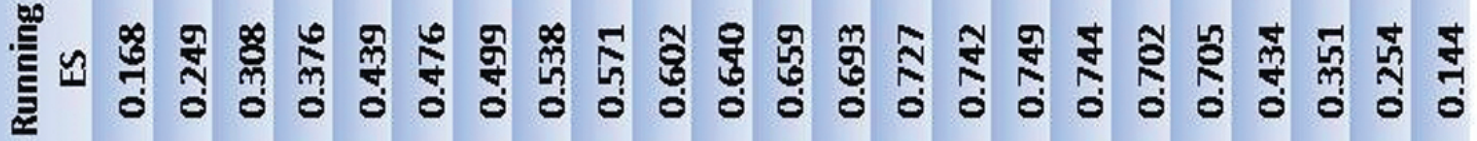

Ŝ

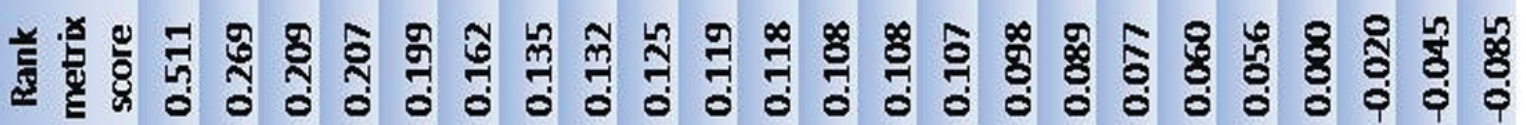

要

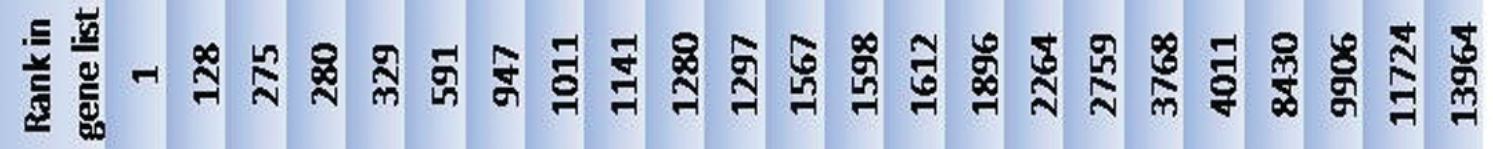

产

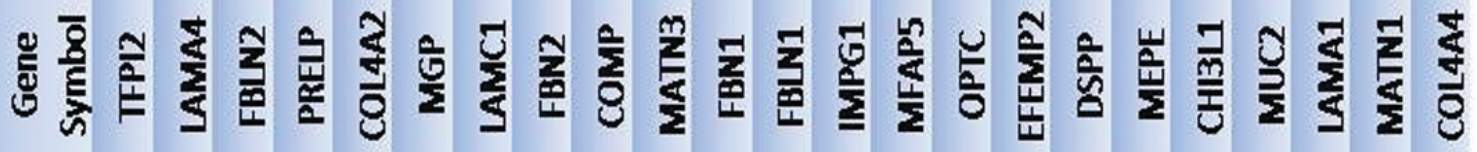

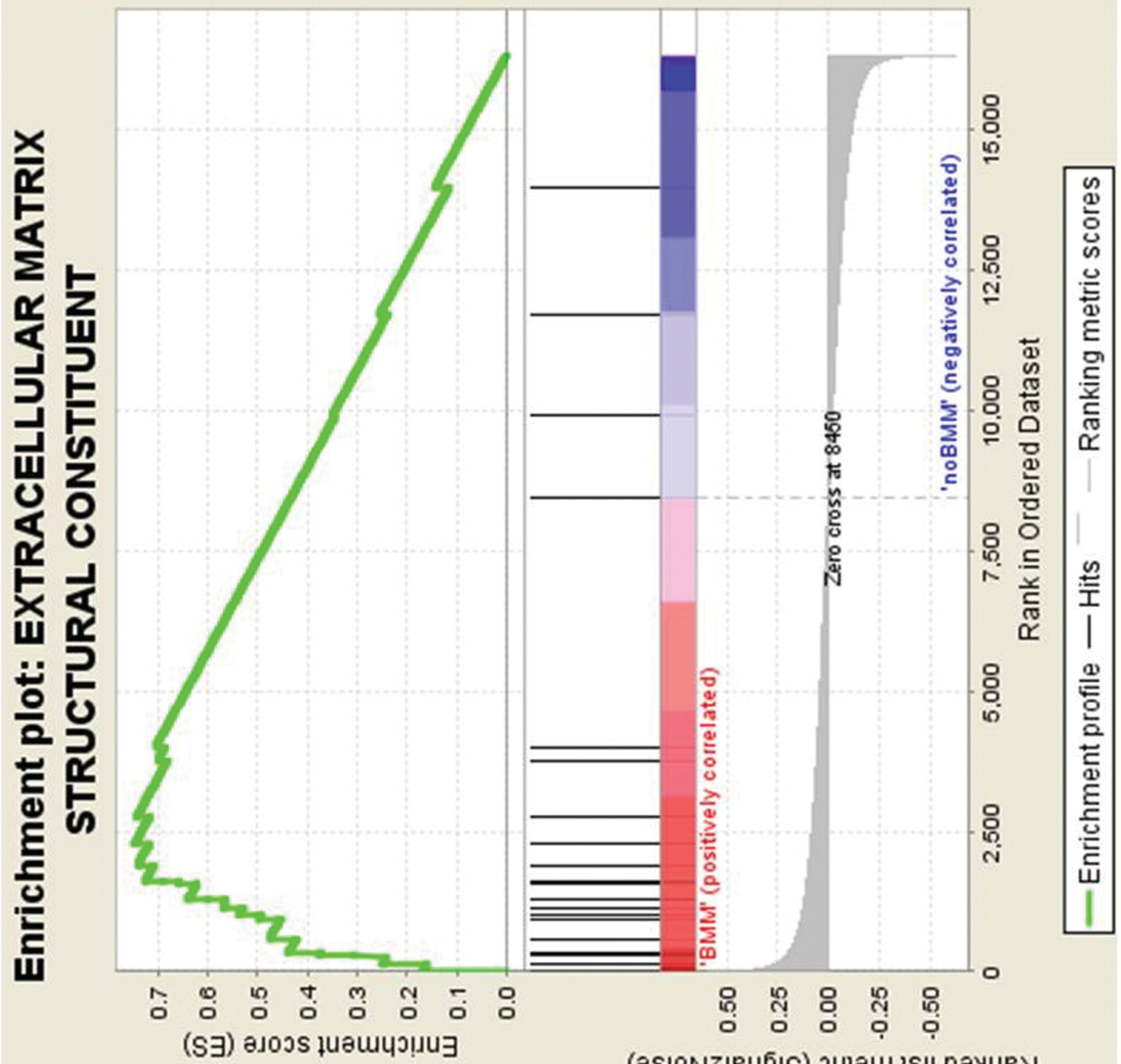

(as!onZIeuб!s) ग!ฺәu §s!! payuey

Downloaded from cancerres.aacrjournals.org on April 27, 2013. @ 2013 American Association for Cancer Research. 
